\title{
Discussion on Big Data Application in Finance
}

\author{
Ma Liyun ${ }^{1}$ \\ ${ }^{1}$ University of Northwestern Polytechnical University, 710000
}

\begin{abstract}
With the continuous development of the Internet, big data have been reflected in various industries. In the field of finance, using big data can promote the stable development of the financial field and control the unstable factors within a reasonable range. This paper first understands the content of big data, then explains the challenges faced by the application of big data in the financial field, and finally understands the strategy of big data application in the financial field, which provides a reference for the research of relevant personnel.
\end{abstract}

\section{Introduction}

The emergence of big data can help the development of the financial field. We can innovate the products of banks, securities and other industries, further improve the level of information in the financial field, and promote the continuous improvement of the structure of the financial field by effectively applying big data to the financial field.Therefore,we should be able to analyze deeply and take corresponding measures to help the development of financial field in the process of using big data.

\section{Big data content}

\subsection{Big Data Connotation}

Big data refers to the integration of a large number of data, we process these data and then improve the efficiency of data application through using advanced technology, and provide help for the development of the industry and improve the decision-making ability of the industry through the use of corresponding data.And this method can also effectively deal with the large amount of data, diversification and other issues to quickly use and analyze the data.

\subsection{Characteristics of Big Data}

With the continuous development of big data, big data has several characteristics: first, the amount of big data is very large. We can excavate the value of them and then make the data meaningful through the analysis of these data. ${ }^{[1]}$ Second is data diversity. It can help related industries to improve predictability, and can also meet the needs of the current society for data through the research and comparison of data.Third is high speed. High speed is not only manifested in the speed of collecting data, but also in the analysis, processing and storage of information, which can better improve the ability of data analysis and processing.Fourth is authenticity. Because the data in big data must be true in order to find the corresponding value from these data.Fifth is complexity. Because the total amount of data is large and there are many kinds of data, there will be complexity in processing.

\section{Problems of big data application in finance}

\subsection{Data Processing Heterogeneous}

In the process of using big data, there is a certain problem of data heterogeneity, which will hinder the smooth application of big data.First of all, the data structure changes from the original data system to the semistructured direction, so we need to pay attention to it in the process of application. ${ }^{[2]}$ Secondly, there are many sources of data, the data in the financial field come from many aspects, and their main bodies are different, but the number and types of mobile devices are more and more, and then more and more data are generated. The meaning of each data is different, which requires big data to analyze it.Finally, the storage method has changed. In order to make better use of big data, it will transform its type in the process of collecting and sorting data, which will increase the difficulty of data processing to a certain extent.

\subsection{Management Risk Prevention and Control}

The data in the financial field are uncertain, not only in quantity, but also in quality. Therefore, there will be a lot of risks in the process of using big data to deal with problems, the biggest risk is decision-making risk for financial enterprises, if the risk is not effectively dealt with, which will directly affect the economic benefits of enterprises.For the related enterprises in the financial field, the decision makers should be able to use big data reasonably, evaluate the risks in it effectively, and avoid 
the wrong decisions. ${ }^{[3]}$ In addition, in order to reduce the emergence of decision-making, we should be able to make a comprehensive evaluation of the decisions formed under big data, so as to ensure the reasonable application of big data in the financial field.

\subsection{Network Data Security}

In the financial field of big data, personal data accounts for a large proportion, and data plays a very important role for individuals.However, the current Internet finance is still in the development stage, which lacks of comprehensive supervision and fail to take correct protection measures for data, it is easy to lead to the random use of personal data and affect the stable development of the financial field seriously.Fundamentally, the reason for the leakage of personal data is that there is not enough cost, or the relevant system is not accurate enough, which affects the smooth implementation of big data in the financial field.

\section{Specific application of big data in the financial field}

\subsection{Enterprise product evaluation}

In the process of financial development, enterprises are the main body, so the products and market operation introduced by the times are very important.The roles of big data in enterprise products has several aspects: first, in product design, enterprises can make specific analysis through big data, effectively control product costs, and then obtain ideal economic benefits for enterprises. ${ }^{[4]}$ Second, in product production, enterprises can optimize production links by using big data to ensure the smooth completion of product production, and can better ensure product quality.Third, in product sales, enterprises price new products by comparing the prices of similar products in the market, so that they can have certain advantages in market competition.For example, according to market demand, a department store uses big data system to compare the price of more than 70 million goods.Finally, after producing products and putting them into the market, enterprises can choose and sell according to the specific consumption ability and preference of each region in big data, which can help enterprises to obtain greater economic benefits.

\subsection{Forecasting Financial Sector Risk}

For the financial field, it will be affected by many aspects, such as industrial structure, stock market and so on. In order to make the financial field develop steadily, it is necessary to construct the corresponding risk prevention system actively. ${ }^{[5]}$ Through the use of big data, we can collect relevant information and data in the financial field in time, and then clarify the specific development trend of stocks and bonds, so as to prevent the potential risk problems in the financial field, and actively do the corresponding measures to reduce the losses in this area and promote the stable development of the financial industry, as shown in figure 1.In view of the risk of the financial industry, there are many sources. In the past, the financial field will take remedial measures only after the risk appears, which will bring economic losses to the corresponding enterprises. Through the use of big data, you can prepare ahead of time and reduce losses.

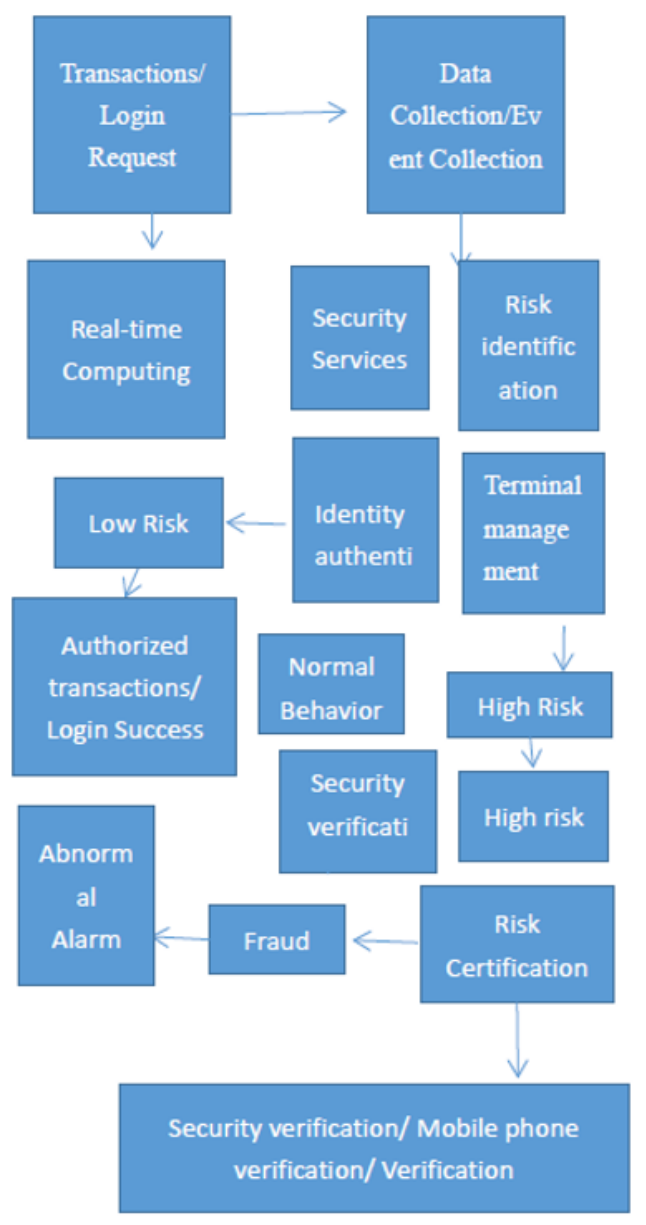

Fig1. Big Data Analysis Process

\subsection{Establishing a credit system}

In the financial field, if you want to effectively borrow, bond and so on, then there needs to be a trust relationship as support.For example, in the financial field, there is no effective understanding of the borrower's own actual situation and credit, so it is easy to pay off debts in time or in debt.Because of the lack of links between regions, even if the borrowers themselves have credit problems, they can use other methods to borrow money because of the lack of circulation of information, which will seriously affect the stability of financial markets. Through the use of big data, we can solve this problem very well, establish contact in various regions, construct user credit system, and then warn the people with credit crisis to provide help for the stable development of the financial field.

\subsection{Personalized Precision Marketing}

For big data, it not only has the function of collecting credit data, but also can analyze the behavior of people in 
the financial field. ${ }^{[6]}$ From the current common Taobao software point of view, it can directly base on the user's consumption and browsing habits to analyze, and then push goods of interest to the users, so that the personalized processing of financial services can be realized very well. Through the effective push of these products, we can effectively increase the sales volume of the corresponding products.

\subsection{Optimizing Financial Operations}

In the process of optimizing its financial operation, we will first understand the sales situation of different financial products in different sales channels by collecting data. Through this method, we can adjust the way of sales and cooperation.At the same time, it can also understand the characteristics of users through big data, and then innovate according to the needs of users to ensure that the products can meet the requirements of users.In addition, the use of big data can also make the financial sector and users better contact, but also help the financial sector to tap quality customers.From the financial industry staff, it is possible to use big data to collect and analyze the staff information, select the staff with high professional level and good comprehensive quality, and promote the stable development of the financial field.

\section{CONCLUTION}

In a word, with the continuous improvement of the current level of science and technology, big data plays a very important role in the marketing, operation and so on in the financial field.Therefore, in the process of application, we need to actively optimize and understand the possibility of using big data in the financial field, so as to better improve the specific application effect of big data in the financial field and promote the development of our society in a better direction.

\section{References}

1. Li Jianpu. Big Data Technology for Financial Research [J].Think tank era 2020(12):44-45.

2. Zhang Bei. Application of big data Technology in Finance and its Regulation [J].Journal of Beijing Vocational College of Economics and Management ,2020,35(01):16-23 33.

3. Zhao Yun. Application of big data in Finance [J].Research Fortune Today 2020(01):40.

4. Yan Qiang. Application Practice and Prospect of Internet Big Data in the Field of Microfinance [J]. Tsinghua Financial Review 2019(03):102-104.

5. Zhuang Xudong. Application and Influence of Big Data in the Field of Finance [J].The Age of Financial Science and Technology 2019(02):29-32.

6. Wan Haogo. Application of big data in Financial Field [J].Communication World ,2018,25(12):61-62. 